\title{
Antimicrobial Activity of Fatty Acid Salts Against Microbial in Koji-Muro
}

\author{
Aya TANAKA ${ }^{1}$, Mariko ERA ${ }^{1}$, Takayoshi KAWAHARA ${ }^{2}$, Takahide KANYAMA ${ }^{2}$, and Hiroshi MORITA ${ }^{3, a}$ \\ ${ }^{1}$ Graduate School of Environmental Engineering, the University of Kitakyushu in Fukuoka, JAPAN \\ ${ }^{2}$ Shabondama Soap Co., Ltd. JAPAN \\ ${ }^{3}$ Faculty of Environment Engineering, the University of Kitakyushu in Fukuoka, JAPAN
}

\begin{abstract}
Aspergillus niger and Aspergillus oryzae are used as koji fungi in the spot of the brewing. Since koji-muro (room for making koji) was a low level of airtightness, microbial contamination has long been a concern to the alcoholic beverage production. Therefore, we focused on the fatty acid salt which is the main component of soap. Fatty acid salts have been reported to show some antibacterial and antifungal activity. This study aimed to find the effectiveness of the fatty acid salt in koji-muro. Nine fatty acid salts were tested. The result, C12K was antibacterial effect against $B$. subtilis. $\mathrm{C} 10 \mathrm{~K}$ and $\mathrm{C} 12 \mathrm{~K}$ was antifungal effect against $R$. oryzae. These results suggest $\mathrm{C} 12 \mathrm{~K}$ has potential in the field of koji-muro.
\end{abstract}

\section{Introduction}

Fungus is ubiquitous in the indoor environment, and breed in the foods such as vegetables and grains, causing corruption and deterioration of these foods in some cases. Bacteria and yeast can be cited as a fellow of other microbial.

Aspergillus species are common contaminants of starchy foods including bread and potatoes. But, Aspergillus niger and Aspergillus oryzae are used as koji fungi in the spot of the brewing. Since koji-muro (room for making koji) was a low level of airtightness, microbial contamination has long been a concern to the alcoholic beverage production. Typical causes of microbial contamination include Rhizopus species in the fungi and Bacillus species in the bacteria. Rhizopus species are called "kumonosukabi" in Japanese, and has been used as koji fungi in Asia other than Japan. Bacillus species include Bacillus subtilis in the typical ones. It is known to shape a durable organ of spores when the growth environment is deteriorated. It has been taken a variety of countermeasure in the current situation to microbial contamination. As an example, the method can be mentioned that using ethanol and invert soap and the fumigation. However, the former is the effect and persistence of low against fungus and spores is a problem. The latter can only be done at the end of the season because it is too powerful.

Therefore, we focused on the fatty acid salt which is the main component of soap. Also, it is an alkali metal salt consisting of alkali and fatty acid $\left(\mathrm{CH}_{3}-(\mathrm{R})-\mathrm{COOH}\right)$, which is a kind of anionic surfactant. It is used as many industrial material. Fatty acids vary in length and degree of saturation, and naturally occurring fatty acids have a chain length of 4 to 28 carbons, which may be saturated

\footnotetext{
a Corresponding author: morita@kitakyu-u.ac.jp
}

or unsaturated [1]. Moreover, it is known that there is antibacterial activity to bacteria, such as Staphylococcus aureus and Eschrichia coli [2-4]. So this study examined antimicrobial activities against Aspergillus oryzae, Rhizopus oryzae and Bacillus subtilis.

This study aimed to find the effectiveness of the fatty acid salt in koji-muro as antimicrobial agents.

\section{Detail Experimental}

\subsection{Source and preparation of fatty acid salts}

Table 1 show the fatty acid salts used in the experiment. Nine fatty acids were tested. Butyric acid (C4:0), caproic acid (C6:0), and linoleic acid (C18:2) were obtained from Wako Pure Chemical Industries, Ltd., Osaka, Japan. Caprylic acid (C8:0), capric acid (C10:0), lauric acid (C12:0), myristic acid (C14:0), oleic acid (C18:1), and linolenic acid (C18:3) were obtained from Tokyo Chemical Industry Co., Ltd.

Hydrated mixtures of fatty acid salts in solution were prepared by gravimetric determination, using fatty acids, $\mathrm{KOH}$ : potassium hydroxide pellets (Wako Pure Chemical Industries, Ltd., Osaka, Japan) and water.

Samples were prepared at $350 \mathrm{mM}$ concentrations. The samples were then stirred for $2 \mathrm{~h}$ at $75^{\circ} \mathrm{C}$. $\mathrm{KOH}$ aq was added to yield theoretical neutralization at $\mathrm{pH} 10.5$ of fatty acid salts. Potassium butyrate $(\mathrm{C} 4 \mathrm{~K})$, potassium caproate $(\mathrm{C} 6 \mathrm{~K})$, potassium caprylate $(\mathrm{C} 8 \mathrm{~K})$, potassium caprate $(\mathrm{C} 10 \mathrm{~K})$, potassium laurate $(\mathrm{C} 12 \mathrm{~K})$, potassium myristate $(\mathrm{C} 14 \mathrm{~K})$, potassium oleate $(\mathrm{C} 18: 1 \mathrm{~K})$, potassium linoleate $(\mathrm{C} 18: 2 \mathrm{~K})$, potassium linolenate $(\mathrm{C} 18: 3 \mathrm{~K})$, and the blank were all adjusted using a $\mathrm{KOH} \mathrm{pH}$-adjusted solution (pH 10.5). All fatty acid salts and the $\mathrm{KOH} \mathrm{pH}-$ 
adjusted solution were filter-sterilized at low temperature (4-6 ${ }^{\circ} \mathrm{C}$ ) using a $0.20-\mu \mathrm{m}$ Millipore filter (Toyo Roshi Kaisya, Ltd., Tokyo, Japan) [5].

Table 1. Samples preparation; FAS

\begin{tabular}{|c|}
\hline C4K : Potassium btyrate \\
\hline $\mathrm{C} 6 \mathrm{~K}:$ Potassium caproate \\
\hline $\mathrm{C} 8 \mathrm{~K}:$ Potassium caprylate \\
\hline $\mathrm{C} 10 \mathrm{~K}:$ Potassium caprate \\
\hline $\mathrm{C} 12 \mathrm{~K}:$ Potassium laurate \\
\hline $\mathrm{C} 14 \mathrm{~K}:$ Potassium myristate \\
\hline $\mathrm{C} 18: 1 \mathrm{~K}:$ Potassium oleate \\
\hline $\mathrm{C} 18: 2 \mathrm{~K}:$ Potassium linoleate \\
\hline $\mathrm{C} 18: 3 \mathrm{~K}:$ Potassium linolenate \\
\hline Control $: \mathrm{KOH}$ pH-adjusted solution \\
\hline
\end{tabular}

\subsection{Fungal strains and growth conditions}

A. oryzae (Akita konnno store, Japan), R. oryzae NBRC 4716 and $B$. subtilis NBRC 3335 were obtained from the NBRC (Biological Resource Center, NITE, Tokyo, Japan).

The fungi were initially grown on Potato Dextrose Agar (PDA: Nissui Pharmaceutical Co., Ltd., Tokyo, Japan) in the dark and the culture stocks were stored at $4{ }^{\circ} \mathrm{C}$. Plant-pathogenic fungi were routinely sub-cultured on PDA in slants in the dark at $30{ }^{\circ} \mathrm{C}$ so that the fresh cultures were available for later use [5].

\subsection{Preparation of spore suspensions}

Fungi were grown on PDA slants at $30{ }^{\circ} \mathrm{C}$ until well sporulated, approximately 10-14 d. Spores were harvested in sterile distilled water using a sterile inoculation loop and gentle agitation; a drop of $0.005 \%$ sulfosuccinic acid bis (2-ethylhexyl) ester sodium salt and $0.9 \% \mathrm{NaCl}$ were added to aid wetting of the spores. The spore concentration was determined by counting using a hemacytometer (Thoma, Sunlead Glass Corp., Saitama, Japan). The initial spore concentration was adjusted to $3.0 \times 10^{4}$ spores $/ \mathrm{mL}[5]$.

\subsection{Preparation of cell suspensions}

The subcultures were incubated at $30{ }^{\circ} \mathrm{C}$ for 1 day. Growth was harvested with autoclaved sterilized water. The bacteria were sedimented by centrifugation at 4200 rpm for $20 \mathrm{~min}$. Pellets were washed three times with 30 $\mathrm{mL}$ of autoclaved sterilized water each time. Final pellets were suspended in $20 \mathrm{~mL}$ of autoclaved sterilized water. The washed suspensions of Bacillus were used on the day of preparation [6].

\subsection{Effect of fatty acid salts on fungal spores or bacterial cells}

Solutions of $400 \mu \mathrm{L}$ of fatty acid salts (final concentration of $175 \mathrm{mM}$ in the tubes) and $400 \mu \mathrm{L}$ of the spore suspension $\left(3.0 \times 10^{4}\right.$ spores $/ \mathrm{mL}$ or $3.0 \times 10^{5}$ $\mathrm{CFU} / \mathrm{mL}$ ) were prepared in $1.5 \mathrm{~mL}$ plastic tubes. Spores mixed with the $\mathrm{KOH} \mathrm{pH}$-adjusted solution were used as controls. Final $\mathrm{pH}$ of all samples were a range of $\mathrm{pH}$ 9.210.8. The mixtures were incubated at $25{ }^{\circ} \mathrm{C}$. Samples were counted at $0,10,60$, and $180 \mathrm{~min}$ by plating (100 $\mu \mathrm{L})$ on PDA or NA. Fungal colonies were counted after incubation for $2 \mathrm{~d}$ or $10 \mathrm{~d}$ at $30^{\circ} \mathrm{C}$. Viable counts $\left(\log _{10}\right.$ $\mathrm{CFU}$ ) of spore was subtracted from the viable count of the control $\left(\log _{10} \mathrm{CFU}\right)$, and the difference was used as a measure of the antifungal activity. All experiments were performed at least thrice.

\subsection{Determination of minimum inhibitory concentrations (MICs)}

The MIC is defined as the lowest concentration of drug sufficient for inhibiting visible growth of spores after 10 min of incubation. MICs against fungi were determined using the two-fold dilution method [7,8].

Table 2 show two-fold dilution method of fatty acid salts. Each fatty acid salt was separately inoculated with $400 \mu \mathrm{L}$ of $R$. oryzae NBRC 4716 or B. subtilis NBRC 3335 at $3.0 \times 10^{4}$ spores $/ \mathrm{mL}$ or $3.0 \times 10^{5} \mathrm{CFU} / \mathrm{mL}$. 1.5 $\mathrm{mL}$ plastic tubes containing $400 \mu \mathrm{L}$ of each of fatty acid salts were inoculated separately with $400 \mu \mathrm{L}$ of the fungi or bacteria. The tubes, each containing a total volume of $800 \mu \mathrm{L}$, were incubated at $25^{\circ} \mathrm{C}$ for each organism for 10 min. After incubation, samples were plating on PDA or $\mathrm{NA}$, incubated at $30^{\circ} \mathrm{C}$ for $7 \mathrm{~d}$, and then examined for the growth of spores. Following incubation, the end point was visually assessed and expressed in $\mathrm{mM}$. The lowest concentration of the antifungal or antibacterial treatment that inhibited visible growth of the fungi or bacteria after incubation was taken as the MIC of the treatment.

Table 2. Two-fold dilution method of fatty acid salts

\begin{tabular}{|c|c|c|c|c|c|}
\hline \multirow{2}{*}{ Two-fold dilution } & \multicolumn{5}{|c|}{ concentration [mM] } \\
\cline { 2 - 6 } & 175 & 87.5 & 43.8 & 21.9 & 10.9 \\
\hline $\begin{array}{c}\text { fatty acid salts 175 } \\
\text { mM }\end{array}$ & 400 & 200 & 200 & 200 & 200 \\
\hline $\begin{array}{c}\text { KOH pH-adjusted } \\
\text { solution }\end{array}$ & - & 200 & 200 & 200 & 200 \\
\hline
\end{tabular}

\subsection{Other reagents tested}

Linear alkylbenzene sulfonate (LAS, Shabondama Soap Co., Ltd., Japan) is an anionic surfactant similar to fatty acid salts, and was used in this experiment for comparison ( $\mathrm{pH}$ 10.5). LAS was obtained from Shabondama Soap Co., Ltd., Fukuoka, Japan.

LAS composed a sodium salt consisting of linear alkyl benzene sulfonic acid, a number of compounds as with soap. $98 \%$ of compound elaborated LAS are linear alkyl benzene sulfonic acid sodium of 12 carbon chain, the rest is included other carbon chain length. 


\section{Results and Discussion}

\subsection{Antibacterial activity of saturated fatty acid salts against $B$. subtilis}

Figure 1 show the antibacterial activity of saturated fatty acid salts against $B$. subtilis. The average initial population of bacteria at $0 \mathrm{~min}$ in all samples was approximately $3.0 \times 10^{5} \mathrm{CFU} / \mathrm{mL}$. Bacteria was incubated for $1 \mathrm{~d}$. Final concentration of saturated fatty acid salts were $175 \mathrm{mM}$. C12K produced a 5 log-units reduction in the growth of $B$. subtilis NBRC 3335 after incubation for $10 \mathrm{~min}$. Thus, C12K, C18:1K, C18:2K and C18:3K suppressed $99.999 \%$ of bacterial growth. Against B. subtilis NBRC 3335 , C10K produced an antibacterial effect of 5 log-units (suppressing $99.999 \%$ of growth) following incubation for $180 \mathrm{~min}$. C8K and $\mathrm{C} 14 \mathrm{~K}$ produced an antibacterial effect of 4 log-units (suppressing $99.99 \%$ of growth) following incubation for 180 min. However, C4K, C6K, and pH-adjusted solution (control) were ineffective after $180 \mathrm{~min}$. Saturated fatty acid salts exerted an antibacterial activity, and no effect was produced by the $\mathrm{pH}$-adjusted solution alone.

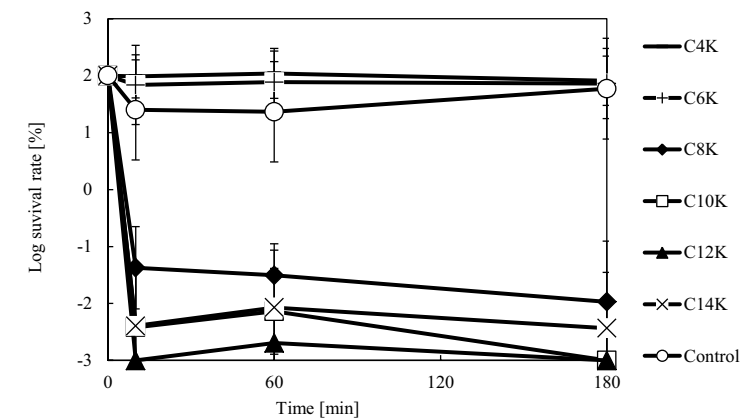

Figure 1. Antibacterial activity of saturated fatty acid salts against $B$. subtilis

Spores were counted at the time of inoculation $(0 \mathrm{~min})$ and after $10,60,180 \mathrm{~min}$ of incubation by means of plating $100 \mu \mathrm{L}$ portions of the same samples. Log survival rate (expressed log $\mathrm{CFU} / \mathrm{mL}$ ) of the samples stored at $30^{\circ} \mathrm{C}$ for $1 \mathrm{~d}$ were enumerated at the specified time points on NA. Symbols: - , $\mathrm{C} 4 \mathrm{~K} ;+, \mathrm{C} 6 \mathrm{~K} ; \diamond, \mathrm{C} 8 \mathrm{~K} ; \square, \mathrm{C} 10 \mathrm{~K} ; \boldsymbol{\Delta}, \mathrm{C} 12 \mathrm{~K} ; \times, \mathrm{C} 14 \mathrm{~K} ; \bigcirc$, Control (KOH pH-adjusted). Experiments were performed in triplicate, and the error bars represent the standard deviation.

Antibacterial activity of saturated fatty acid salts were found to have defferent intensities of the activity by the defference in the carbon chain. In addition, it was revealed that the antibacterial activity of the relatively long saturated fatty acid salts having a carbon chain is high. Thus, we consider the reason why the difference in antibacterial activity by the difference in the number of carbon chain. Hydrophobic groups of the saturated fatty acid salt is fatty acid. Fatty acid has been considered increasing destabilization of cell membranes by being inserted into the phospholipid bilayer of the cell membrane of the bacteria $[9,10]$. Therefore, the saturated fatty acid salts of the short chain saturated fatty acid salts for the hydrophobic group is short, be suspected that did not result in increased destabilization of cell membranes in $B$. subtilis. The saturated fatty acid salt have a medium-chain of hydrophobic group is considered increasing destabilization of cell membranes by a hydrophobic group is inserted into the phospholipid bilayer of the cell membrane of $B$. subtilis, it is believed to have shown an antibacterial effect.

\subsection{Antibacterial activity of unsaturated fatty acid salts against $B$. subtilis}

Figure 2 show the antibacterial activity of unsaturated fatty acid salts against $B$. subtilis. The average initial population of bacteria at $0 \mathrm{~min}$ in all samples was approximately $3.0 \times 10^{5} \mathrm{CFU} / \mathrm{mL}$. B. subtilis was incubated for $1 \mathrm{~d}$. Final concentration of unsaturated fatty acid salts were $175 \mathrm{mM}$. C18:1K, C18:2K and C18:3K produced a $5 \log$-units reduction in the growth of $B$. subtilis NBRC 3335 after incubation for $10 \mathrm{~min}$. Thus, $\mathrm{C} 18: 1 \mathrm{~K}, \mathrm{C} 18: 2 \mathrm{~K}$ and $\mathrm{C} 18: 3 \mathrm{~K}$ suppressed $99.999 \%$ of bacterial growth. However, pH-adjusted solution (control) were ineffective after $180 \mathrm{~min}$. Unsaturated fatty acid salts exerted an antibacterial activity, and no effect was produced by the $\mathrm{pH}$-adjusted solution alone.

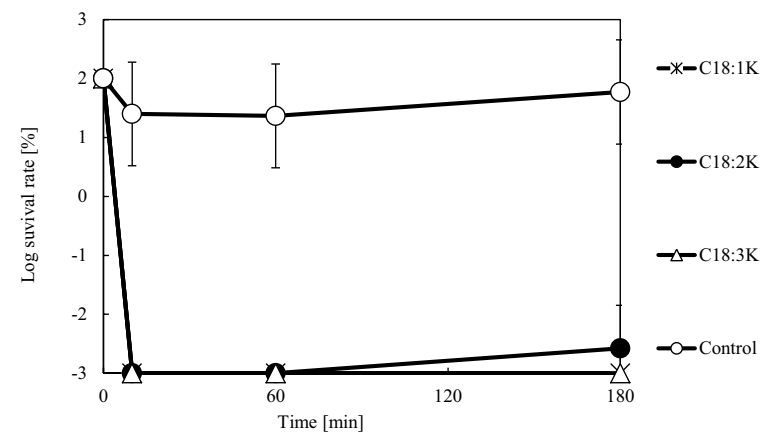

Figure 2. Antibacterial activity of unsaturated fatty acid salts against $B$. subtilis

Spores were counted at the time of inoculation $(0 \mathrm{~min})$ and after $10,60,180$ min of incubation by means of plating $100 \mu \mathrm{L}$ portions of the same samples. Log survival rate (expressed log $\mathrm{CFU} / \mathrm{mL}$ ) of the samples stored at $30^{\circ} \mathrm{C}$ for $1 \mathrm{~d}$ were enumerated at the specified time points on NA. Symbols: $*$, $\mathrm{C} 18: 1 \mathrm{~K} ; \bigcirc, \mathrm{C} 18: 2 \mathrm{~K} ; \triangle, \mathrm{C} 18: 3 \mathrm{~K} ; \bigcirc$, Control $(\mathrm{KOH} \mathrm{pH}-$ adjusted). Experiments were performed in triplicate, and the error bars represent the standard deviation.

Antibacterial activity of unsaturated fatty acid salts were found to have defferent intensities of the activity by the short saturated fatty acid salts. Thus, we consider the reason why the difference in antibacterial activity by the short saturated fatty acid salts. Hydrophobic groups of the unsaturated fatty acid salt is fatty acid same as saturated fatty acid salts. Fatty acid has been considered increasing destabilization of cell membranes by being inserted into the phospholipid bilayer of the cell membrane of the bacteria [9]. The unsaturated fatty acid salt have longchain of hydrophobic group. So we considered increasing destabilization of cell membranes by a hydrophobic group is inserted into the phospholipid bilayer of the cell membrane of $B$. subtilis, it is believed to have shown an antibacterial effect [3].

\subsection{Antifungal activity of saturated fatty acid salts against $R$. oryzae}


Figure 3 show the antifungal activity of saturated fatty acid salts against $R$. oryzae NBRC 4716 . The average initial population of fungus at $0 \mathrm{~min}$ in all samples was approximately $3.0 \times 10^{4}$ spores $/ \mathrm{mL}$. Fungus was incubated for $1 \mathrm{~d}$. Final concentration of fatty acid salts were $175 \mathrm{mM}$. C12K produced a $4 \log$-units reduction in the growth of $R$. oryzae NBRC 4716 after incubation for 10 min. Thus, C12K suppressed $99.99 \%$ of fungal growth. Against $R$. oryzae NBRC 4716, C10K produced an antifungal effect of 4 log-units (suppressing $99.99 \%$ of growth) following incubation for $180 \mathrm{~min}$. C14K produced an antifungal effect of 3 log-units (suppressing $99.9 \%$ of growth) following incubation for $180 \mathrm{~min}$. However, $\mathrm{C} 4 \mathrm{~K}, \mathrm{C} 6 \mathrm{~K}, \mathrm{C} 8 \mathrm{~K}$ and $\mathrm{pH}$-adjusted solution (control) were ineffective after $180 \mathrm{~min}$. Saturated fatty acid salts exerted an antifungal effect, and no effect was produced by the $\mathrm{pH}$-adjusted solution alone.

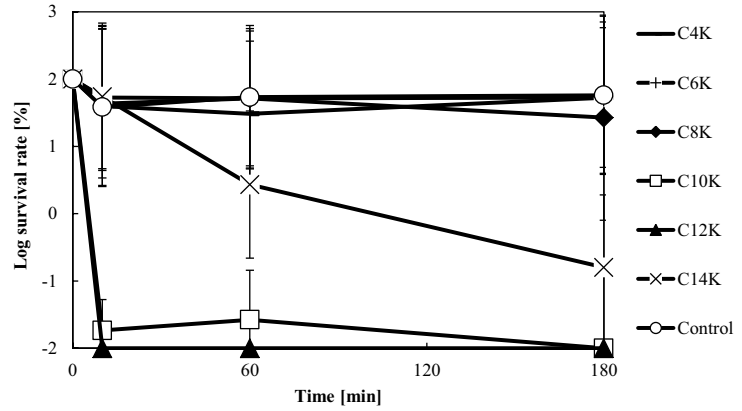

Figure 3. Antifungal activity of saturated fatty acid salts against R. oryzae

Spores were counted at the time of inoculation $(0 \mathrm{~min})$ and after $10,60,180 \mathrm{~min}$ of incubation by means of plating $100 \mu \mathrm{L}$ portions of the same samples. Log survival rate (expressed log $\mathrm{CFU} / \mathrm{mL}$ ) of the samples stored at $30^{\circ} \mathrm{C}$ for $1 \mathrm{~d}$ were enumerated at the specified time points on PDA. Symbols: $\mathrm{C} 4 \mathrm{~K} ;+, \mathrm{C} 6 \mathrm{~K} ; \diamond, \mathrm{C} 8 \mathrm{~K} ; \square, \mathrm{C} 10 \mathrm{~K} ; \boldsymbol{\Delta}, \mathrm{C} 12 \mathrm{~K} ; \times, \mathrm{C} 14 \mathrm{~K} ; \bigcirc$, Control (KOH pH-adjusted). Experiments were performed in triplicate, and the error bars represent the standard deviation.

Antifungal activity of saturated fatty acid salts were found to have defferent intensities of the activity by the defference in the carbon chain. The antimicrobial effect of fatty acids, which are the raw material for the production of fatty acid salts, decrease with increasing chain length, and medium-chain fatty acids exhibit stronger activity than longer chain fatty acids [11]. Thus, the reason for the difference in antifungal activity caused by the difference in the number of carbon chain, it is suspected that showed antifungal activity in fungas spores for the same reason as that discussed antibacterial activity of the fatty acid salt against $B$. subtilis. However, some of the saturated fatty acid salt against $R$. oryzae did not show high antifungal activity. $B$. subtilis are classified as Gram-negative bacteria among the bacteria, so this cell walls is thin compared to the fungas $[3,12]$. Thus, we considered result did not increase the destabilization of the cell membrane of $R$. oryzae because $\mathrm{C} 8 \mathrm{~K}$ is not a sufficient length of the hydrophobic group.

\subsection{Antifungal activity of unsaturated fatty acid salts against $R$. oryzae}

Figure 4 show the antifungal activity of unsaturated fatty acid salts against $R$. oryzae NBRC 4716 . The average initial population of fungus at $0 \mathrm{~min}$ in all samples was approximately $3.0 \times 10^{4}$ spores $/ \mathrm{mL}$. Fungus was incubated for $1 \mathrm{~d}$. Final concentration of unsaturated fatty acid salts were $175 \mathrm{mM}$. C18:1K, C18:2K, C18:3K and $\mathrm{pH}$-adjusted solution (control) were ineffective after 180 min. Unsaturated fatty acid salts exerted an antifungal effect, and no effect was produced by the $\mathrm{pH}$-adjusted solution alone.

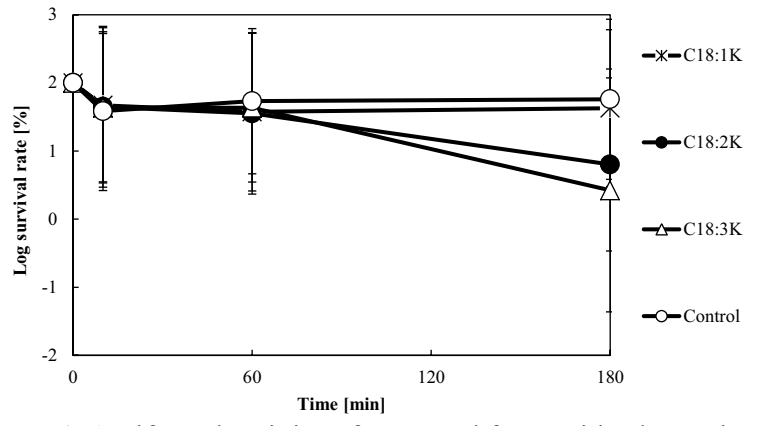

Figure 4. Antifungal activity of saturated fatty acid salts against R. oryzae

Spores were counted at the time of inoculation $(0 \mathrm{~min})$ and after $10,60,180$ min of incubation by means of plating $100 \mu \mathrm{L}$ portions of the same samples. Log survival rate (expressed log $\mathrm{CFU} / \mathrm{mL}$ ) of the samples stored at $30^{\circ} \mathrm{C}$ for $1 \mathrm{~d}$ were enumerated at the specified time points on PDA. Symbols: $*$, $\mathrm{C} 18: 1 \mathrm{~K} ; \bigcirc, \mathrm{C} 18: 2 \mathrm{~K} ; \triangle, \mathrm{C} 18: 3 \mathrm{~K} ; \bigcirc$, Control $(\mathrm{KOH} \mathrm{pH}-$ adjusted). Experiments were performed in triplicate, and the error bars represent the standard deviation.

Antifungal activity of unsaturated fatty acid salts were found to have different intensities of the activity by the saturated fatty acid salts. However, the reason have not been clarified.

\subsection{Antifungal activity of fatty acid salts against A. oryzae}

Figure 5 show the antifungal activity of fatty acid salts against $A$. oryzae. The average initial population of fungus at $0 \mathrm{~min}$ in all samples was approximately $3.0 \times$ $10^{4}$ spores $/ \mathrm{mL}$. Fungus was incubated for $2 \mathrm{~d}$. Final concentration of fatty acid salts were $175 \mathrm{mM}$. No obvious change was observed in tested fatty acid salts against $A$. oryzae. Antifungal effect was not produced by the $\mathrm{pH}$-adjusted solution alone.

So far, fatty acid salts have been observed antimicrobial activity against $R$. oryzae and $B$. subtilis in present study and Penicillium [5] and oral bacteria [13] in previous study, but did not observed antifungal activity against $A$. oryzae.

For future work, we would like to examine the reason for fatty acid salt against $A$. oryzae spores did not showed antifungal activity. 


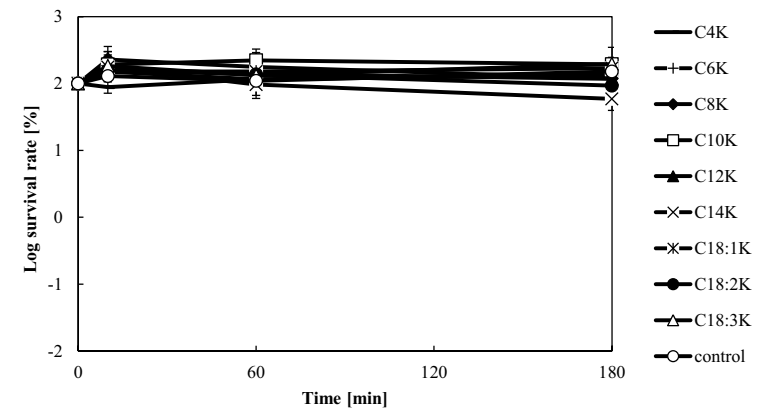

Figure 5. Antifungal activity against $A$. oryzae Spores were counted at the time of inoculation $(0 \mathrm{~min})$ and after $10,60,180 \mathrm{~min}$ of incubation by means of plating $100 \mu \mathrm{L}$ portions of the same samples. Log survival rate (expressed log $\mathrm{CFU} / \mathrm{mL}$ ) of the samples stored at $30^{\circ} \mathrm{C}$ for $2 \mathrm{~d}$ were enumerated at the specified time points on PDA. Symbols: -, $\mathrm{C} 4 \mathrm{~K} ;+, \mathrm{C} 6 \mathrm{~K} ; \diamond, \mathrm{C} 8 \mathrm{~K} ; \square, \mathrm{C} 10 \mathrm{~K} ; \boldsymbol{\Delta}, \mathrm{C} 12 \mathrm{~K} ; \times, \mathrm{C} 14 \mathrm{~K} ; *$, $\mathrm{C} 18: 1 \mathrm{~K} ; \bigcirc, \mathrm{C} 18: 2 \mathrm{~K} ; \triangle, \mathrm{C} 18: 3 \mathrm{~K} ; \bigcirc$, Control $(\mathrm{KOH}$ pHadjusted). Experiments were performed in triplicate, and the error bars represent the standard deviation.

\subsection{Antimicrobial activity of other reagents against $B$. subtilis, $R$. oryzae and $A$. oryzae}

Figure 6 show antimicrobial avtivity of LAS against $B$. subtilis NBRC 3335, R. oryzae NBRC 4716 and A. oryzae (Akita konnno store). The average initial population of bacteria or fungas at $0 \mathrm{~min}$ in all samples was approximately $3.0 \times 10^{5} \mathrm{CFU} / \mathrm{mL}$ or $3.0 \times 10^{4}$ spore $/ \mathrm{mL}$. Bacteria was incubated for $1 \mathrm{~d}$. R. oryzae was incubated for $1 \mathrm{~d}$. A. oryzae was incubated for $2 \mathrm{~d}$. Final concentration of fatty acid salts and LAS was $175 \mathrm{mM}$. LAS produced a $5 \log$-units reduction in the growth of $B$. subtilis NBRC 3335 after incubation for $10 \mathrm{~min}$. Thus, LAS suppressed $99.999 \%$ of bacterial growth. Similar results were obtained when the result of $\mathrm{C} 12 \mathrm{~K}, \mathrm{C} 18: 1 \mathrm{~K}$, C18:2K and C18:3K against $B$. subtilis NBRC 3335 . We would like to examine the reason for the LAS showed high antibacterial activity. LAS is synthetic detergent so it includes a sulfonate salt having an alkyl group with a carbon chain 10-14. Therefore, it suspected that LAS showed antibacterial activity against $B$. subtilis because it include same carbon chain as fatty acid salts.

LAS produced a $4 \log$-units reduction in the growth of R. oryzae NBRC 4716 after incubation for $10 \mathrm{~min}$. Thus, LAS suppressed $99.99 \%$ of fungal growth. Similar results were obtained when the result of $\mathrm{C} 12 \mathrm{~K}$ against $R$. oryzae NBRC 4716. We would like to examine the reason for the LAS showed high antifungal activity. The reason for the antifungal activity is suspected same reason as that antibacterial activity of LAS against $B$. subtilis.

No obvious change was observed in tested in LAS against A. oryzae (Akita konnno store). The reason for the result is suspected same reason as that antifungal activity of fatty acid salts against $A$. oryzae (Akita konnno store).

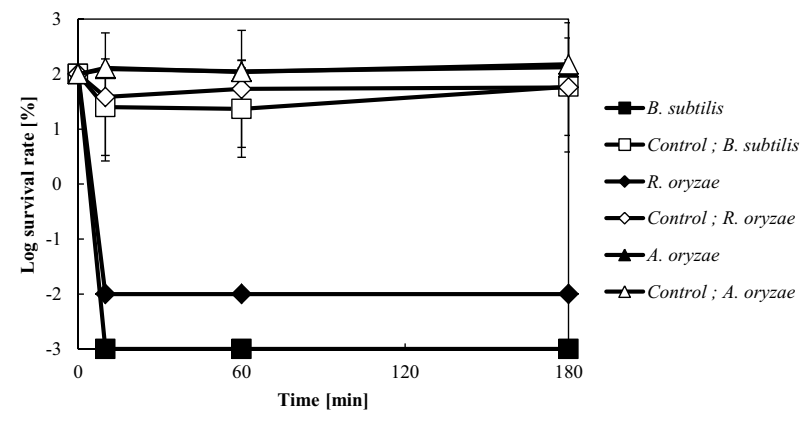

Figure 6. Antimicrovial activity of LAS against B. subtilis, $R$. oryzae and A. oryzae

Spores were counted at the time of inoculation $(0 \mathrm{~min})$ and after $10,60,180 \mathrm{~min}$ of incubation by means of plating $100 \mu \mathrm{L}$ portions of the same samples. Log survival rate (expressed log $\mathrm{CFU} / \mathrm{mL}$ ) of the samples stored at $30^{\circ} \mathrm{C}$ for $1 \mathrm{~d}$ or $2 \mathrm{~d}$ were enumerated at the specified time points on NA or PDA. Symbols: $\square$, B. subtilis; $\square$, Control of B. subtilis; $\bullet, R$ oryzae; $\diamond$, Control of R. oryzae; $\boldsymbol{\Lambda}$, A. oryzae; $\triangle$, Control of $A$. oryzae. Experiments were performed in triplicate, and the error bars represent the standard deviation.

\subsection{MIC of fatty acid salts and LAS}

Two-fold dilution samples of the $175 \mathrm{mM}$ solution inoculated with fungus or bacteria were incubated for 10 min, and then applied to the agar medium, and MICs were determined after $7 \mathrm{~d}$ of culture. The results are shown in Table 3.

First, we describe the result of MIC of fatty acid salts against $B$. subtilis. All samples of fatty acid salts concentrations $>175 \mathrm{mM}$ were required to inhibit fungal growth. Sample of LAS concentrations $>175 \mathrm{mM}$ were required to inhibit fungal growth.

Next, we describe the result of MIC of fatty acid salts against $R$. oryzae. $\mathrm{C} 10 \mathrm{~K}$ and $\mathrm{C} 12 \mathrm{~K}$ at $175 \mathrm{mM}$ inhibited the growth of $R$. oryzae NBRC 4716 for $7 \mathrm{~d}$. However, concentrations $>175 \mathrm{mM}$ of the other samples were required to inhibit fungal growth. LAS at $87.5 \mathrm{mM}$ inhibited the growth of $R$. oryzae NBRC 4716 for $7 \mathrm{~d}$.

Table 3. MIC against $B$. subtilis

\begin{tabular}{|c|c|c|}
\hline \multirow{2}{*}{ FAS } & \multicolumn{2}{|c|}{ MIC [mM] } \\
\cline { 2 - 3 } & B. subtilis & R. oryzae \\
\hline C4K : Potassium btyrate & $>175$ & $>175$ \\
\hline C6K : Potassium caproate & $>175$ & $>175$ \\
\hline C8K : Potassium caprylate & $>175$ & $>175$ \\
\hline C10K : Potassium caprate & $>175$ & 175 \\
\hline C12K : Potassium laurate & $>175$ & 175 \\
\hline C14K : Potassium myristate & $>175$ & $>175$ \\
\hline C18:1K : Potassium oleate & $>175$ & $>175$ \\
\hline C18:2K : Potassium linoleate & $>175$ & $>175$ \\
\hline C18:3K : Potassium linolenate & $>175$ & $>175$ \\
\hline LAS & $>175$ & 87.5 \\
\hline
\end{tabular}




\section{Conclusions}

In this study, $\mathrm{C} 12 \mathrm{~K}, \mathrm{C} 18: 1 \mathrm{~K}, \mathrm{C} 18: 2 \mathrm{~K}$ and $\mathrm{C} 18: 3 \mathrm{~K}$ showed the highest antibacterial activity (5 log-units) against B. subtilis NBRC 3335, suppressing 99.999\% of bacterial growth (Figure 1,2). A control solution at the same $\mathrm{pH}$ as the fatty acid salt solutions did not affect bacterial growth. So we concluded that the antibacterial activity was due to the fatty acid salts themselves, not $\mathrm{pH}$. Also, from the determination of MIC, it was found to be bacteriostatic action. In addition, the antibacterial activity of LAS was same as fatty acid salts.

Next, C12K showed the highest antifungal activity (4 log-units) against $R$. oryzae NBRC 4716, suppressing $99.99 \%$ of fungal growth (Figure 3, 4). A control solution at the same $\mathrm{pH}$ as the fatty acid salt solutions did not affect fungal growth. So we concluded that the antifungal activity was due to the fatty acid salts themselves, not $\mathrm{pH}$. Also, the antibacterial activity of LAS was same as fatty acid salts.

No obvious change was observed in tested fatty acid salts against $A$. oryzae (Akita konnno store) (Figure 5, 6).

Additional research is required to have high antimicrobial activity with other reagent.

\section{References}

1. S. L. Sado-kamdem, L. Vannini, M. E. Guerzoni, Effect of $\alpha$-linolenic, capric and lauric acid on the fatty acid biosynthesis in Staphylococcus aureus, Int. J. Food Microbiol, 129, 288-294, (2009)

2. S. Khulusi, H. A. Ahmed, P. Patel, M. A. Mendall and T. C. Northfield, The effects of unsaturated fatty acids on Helicobacter pylori in vitro, J. Med. Microbiol, 42, 276-282, (1995)

3. A. P. Desbois; V. J. Smith, Antibacterial free fatty acids : activities, mechanisms of action and biotechnological potential, Applied Microbiology and Biotechnology, 85, 1629-1642, (2010)

4. S. A. Baskaran, V. Bhattaram, Induupadhyaya, A. Upadhyay, A. Kollanoor-johny, D. Schreiber, JR., and K. Venkitanarayanan, Inactivation of
Escherichia coli O157:H7 on Cattle Hides by Caprylic Acid and b-Resorcylic Acid, Journal of Food Protection, 76, 318-322, (2013)

5. M. Era, S. Sakai, A. Tanaka, T. Kawahara, T. Kanyama, H. Morita, Antifungal Activity of Fatty Acid Salts Against Penicillium pinophilum, Japan Journal of Food Engineering, 16, 99-108, ( 2015)

6. R. Wadowsky, T. M. Wilson, N. J. Kapp, A. J. West, J. M. Kuchta, S. J. States, J. N. Dowling, and R. B. Yee, Multiplication of Legionella spp. in tap water containing Hartmannella vermiformis, Environmental Microbiology, 57, 1950-1955, (1991)

7. A. Kollanoor, P. Vasudevan, M. K. M. Nair, T. Hoagland, K. Venkitanarayanan, Inactivation of bacterial fish pathogens by medium chain lipid molecules (caprylic acid, monocaprylin and sodium caprylate), Aquaculture Res., 38, 1293-1300, (2007)

8. K. Takashima, Mold inspection manual color atlas (Kabi Kensa Manuaru Kara Zufu), Techno System Co., Ltd., 214-215, (2009)

9. T. Kitahara, N. Koyama, J. Matsuda, Y. Aoyama, Y. Hirakata, S. Kamihira, S. Kohno, M. Nakashima, and H. Sasaki, Antimicrobial Activity of Saturated Fatty Acids and Fatty Amines against MethicillinResistant Staphylococcus aureus, Biol. Pharm. Bull, 27, 1321-1326, (2004)

10. L. Ababouch, A. Chaibi, F.F. Busta, Inhibition of bacterial spore growth by fatty acids and their sodium salts, J. Food Prot., 55, 980-984, (1992)

11. L.L. Wang, E. A. Johnson, Inhibition of Listeria monocytogenes by fatty acids and monoglycerides, App. Env. Microbiol., 58, 624-629, (1992)

12. D. Mitoraj, A. Janczyk, M. Strus, H. Kisch, G. Stochel, P. B. Heczko and W. Macyk, Visible light inactivation of bacteria and fungi by modified titanium dioxide, Photochem. Photobiol. Sci., 6, 642648, (2007)

13. M. Masuda, M. Era, T. Kawahara, T. Kanyama, H. Morita, Antibacterial Effect of Fatty Acid Salts on Oral Bacteria, Biocontrol Science, 20, 209-213, (2015) 